\title{
A primeira proposta de um supercontinente primitivo no opúsculo de 1764, do barão von Hüpsch-Lonzen
}

\author{
Nelson Papavero \\ Pablo Rubén Mariconda \\ Maurício de Garvalho Ramos
}

\section{Buffon e a união dos continentes da África e da AmÉrica do Sul}

Um dos mais desafiadores padrões biogeográficos que Buffon devia explicar era o da presença de grupos de mamíferos sul-americanos (por exemplo, os marsupiais) ou, pelo menos, aquilo que se costumava assim considerar no século XVIII. Entre as várias tentativas de explicação, há uma que nos interessa particularmente, a saber, a postulação, na Histoire naturelle (História natural) de 1766, de uma antiga união dos continentes da África e da América do Sul. Os grupos de mamíferos que eram considerados endêmicos na América do Sul, por terem sido originalmente criados na Eurásia, teriam passado para o primeiro continente pela África, permanecendo na América porque teriam encontrado as condições apropriadas, extinguindo-se no resto do mundo, após a separação dos continentes. Apreciemos, na íntegra, o texto de Buffon em que essa hipótese explicativa é explorada:

Assim, de dez gêneros e quatro espécies isolados aos quais nos atribuímos a tarefa de reduzir todos os animais próprios e particulares ao Novo Mundo, não há mais do que dois, a saber, o gênero dos jaguares, das jaguatiricas etc. e a espécie do porco do mato com suas variedades, que se possa relacionar com algum fundamento aos animais do antigo continente. Os jaguares e as jaguatiricas podem ser considerados como espécies de leopardos eu de panteras; e o porco do mato como uma espécie de porco. A seguir, existem cinco gêneros e uma espécie isolada, a saber, a espécie da lhama e os gêneros dos bugios, dos sagüis, dos gambás, das pacas e dos tamanduás, que se pode comparar, mas de maneira equivocada e bastante afastada, ao camelo, aos cercopitecídeos, às doninhas, à lebre e aos pangolins; e, por fim, faltam quatro gêneros e duas espécies isoladas, a saber, os quatis, os tatus, as preguiças, a anta e a capivara, que não podem ser relacionadas 


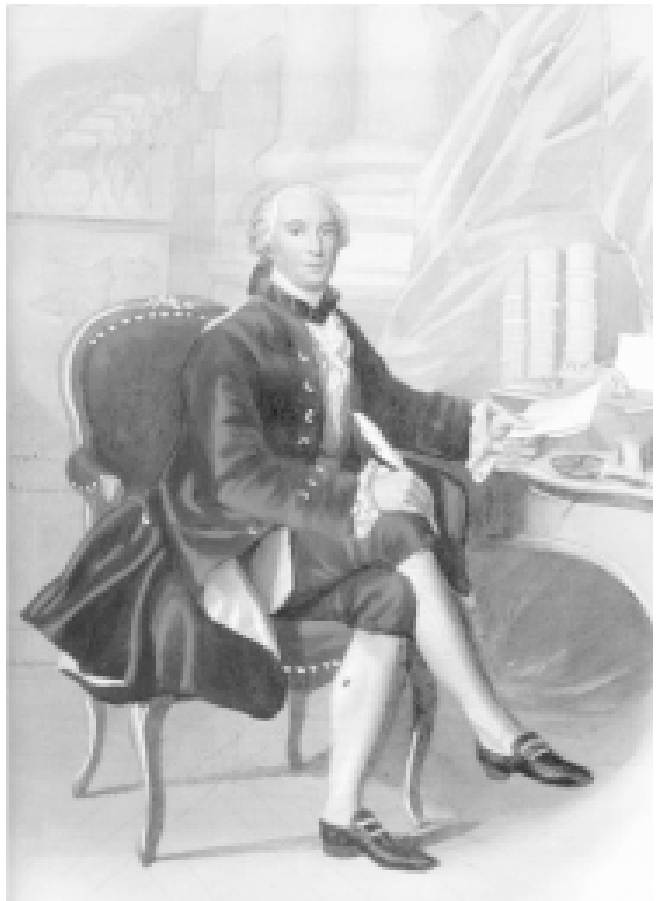

Figura 1: Georges Louis Buffon à mesa de trabalho em gravura de Prudhomme. nem comparadas a nenhum dos gêneros ou das espécies do velho continente. É mais razoável pensar que em outros tempos os dois continentes eram contíguos ou contínuos e que as espécies que se tinham acantonado nessas paragens do novo mundo, porque tinham encontrado nelas a terra e o céu mais convenientes a sua natureza, acabaram presas e separadas das outras pela irrupção dos mares quando estes dividiram a Africa da América. Esta causa é natural e pode-se imaginar outras semelhantes e que produziriam o mesmo efeito. Por exemplo, se tivesse acontecido que o mar irrompesse na Ásia, de oriente para poente, e que separasse do resto do continente as terras meridionais da África e da Ásia, todos os animais que são próprios e particulares dessas regiões sulinas, tais como os elefantes, os rinocerontes, as girafas, as zebras, os orangotangos etc. encontrar-se-iam, relativamente aos outros, na mesma situação em que estão atualmente aqueles da América meridional; eles estariam inteira e absolutamente separados daqueles das regiões temperadas, e estaríamos errados em procurar para eles uma origem comum e em querer aproximá-los das espécies e dos gêneros que povoam essas regiões, com base no único fundamento de que eles teriam com esses últimos alguma semelhança imperfeita ou alguma relação afastada.

Énecessário, portanto, para dar a razão da origem desses animais, voltar aos tempos em que os dois continentes ainda não estavam separados; é necessário lembrar as primeiras mudanças que aconteceram sobre a superfície do globo; é necessário, ao mesmo tempo, representar-se a redução das duzentas espécies de animais quadrúpedes a trinta e oito famílias; e ainda que esse não seja o estado da natureza tal qual ela chegou até nós e tal qual o temos representado, e que seja, ao contrário, um estado muito mais antigo e que não podemos atingir a não ser por induções e relações quase tão fugidias quanto o tempo que parece ter-lhes apagado os traços, tentaremos ainda assim retornar, por meio dos fatos e dos monumentos ainda existentes, a essas primeiras idades da natureza, apresentando as épocas que nos parecerem claramente indicadas (Buffon, 1868, p. 144). 


\section{O BARÃO VON HÜPSGH}

\section{E A PRIMEIRA PROPOSTA DE UM "supergontinente dA PANGeA"}

A hipótese de Buffon muito provavelmente se inspirava em um livreto publicado em Colônia em ${ }_{17} 64$ e, portanto, dois anos antes, por Johann Wilhelm Karl Adolph von Honvlez-Ardenn, barão von Hüpsch-Lonzen com o título Physikalische Abhandlung von dervormaligen Verknüpfung und Absonderung der alten und neuen Welt, und der Bevölkerung Westindiens (Dissertação física sobre a anterior união e separação do Velho e Novo Mundo e o povoamento das Índias Ocidentais). Possuidor de uma valiosíssima coleção de obras de arte e de objetos naturais, que deram lugar à fundação do Museu de Darmstadt, o barão von Hüpsch foi também o autor do livro Geophänomenologie (Geofenomenologia) (1764,b) e de um trabalho sobre fósseis, (1768, traduzido ao francês em 1771) [figura 2].

A “descoberta” do livro do barão von Hüpsch sobre a união e separação do Velho e Novo Mundo é devida a G. Quarg que em 1983 publicou um pequeno artigo sobre ele, sem receber infelizmente a merecida atenção.

Como indica o título, o tema principal da obra é a união primordial e a posterior separação do Velho Mundo (Europa, Ásia e África) e do Novo Mundo (Índias Ociden-

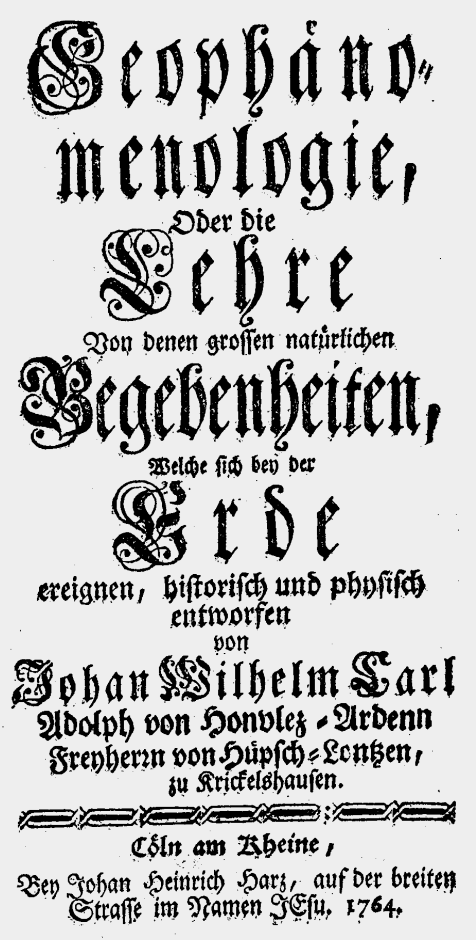

Figura 2: Página-título da Geofenomenologia do barão von Hüpsch-Lonzen. tais ou América), bem como o povoamento deste último por homens e animais a partir do primeiro. A separação teria ocorrido pela invasão dos oceanos do hemisfério norte entre os dois blocos continentais. A causa de tal evento é associada por von Hüpsch a uma série de fenômenos geológicos de grande impacto, principalmente violentos movimentos sísmicos subterrâneos. Em sua argumentação, o autor evoca uma série de eventos similares, mais recentes e locais, envolvendo terremos associados ao fluxo e ao refluxo dos mares. O leitor poderá perceber um esforço considerável em apresentar grande quantidade de provas físicas consistentes para sustentar a suposição central do autor.

A obra também explora problemas biogeográficos, cuja importância poderá ser melhor percebida a partir das considerações históricas que apresentamos a seguir. 


\section{Tradugianismo biogeográfico E GRIAGionismo}

Um dos primeiros problemas considerados pelos Padres fundadores da Igreja foi o do traducianismo, enquanto oposto ao criacionismo. Traducianismo (do Latim tradux, o sarmento de videira, que se faz passar de uma vinha a outra; traduco: conduzir além, fazer passar, levar) era um modo de explicar a origem das almas humanas individuais, que seriam transmitidas de pai para filho por geração e por meio do esperma, tal como outra característica qualquer, segundo a teoria então dominante da pangênese (cf. Papavero \& Balsa, 1986; Papavero, Llorente-Bousquets \& Espinosa-Organista, 1995a). A alma paterna, desde Adão (que foi o único a ter recebido uma alma imortal diretamente das mãos de Deus), reproduziria por brotamento, passando com o esperma a seus filhos, destes a seus filhos e assim por diante.

O criacionismo, por outro lado, admite a criação múltipla e independente (por Deus) das almas, formando-se uma nova alma para cada ser humano criado.

Papavero \& Balsa (1986) adaptaram esses dois termos à biogeografia, chamando criacionismo à ausência de comunhão de descendência entre as espécies vivas; estas teriam uma origem múltipla e independente, seja no espaço, seja no tempo, sejam em ambos, como é o caso da criação das espécies animais e vegetais criadas por Deus na semana da criação, no jardim do Éden (Gênese I, 2). Na biogeografia, o criacionismo admite a existência de múltiplos "centros de origem (ou de criação)", cada qual com uma biota distinta. Por traducianismo entenderemos a existência de comunhão de descendência entre as espécies vivas, derivadas de um único ancestral comum (tal como admitido pela teoria da evolução). Na biogeografia, as espécies originar-se-iam de um único "centro de origem (ou criação)", dispersando-se depois radialmente até ocupar toda a face da Terra, sofrendo ou não modificações morfológicas à medida que se espalham pelos continentes. Assim, o livro do Gênese é traducianista do ponto de vista da biogeografia e é criacionista do ponto de vista das espécies (cf. Papavero, LlorenteBousquets \& Espinosa-Organista, 1995a; Papavero, Teixeira \& Llorente-Bousquets, 1997).

\section{Alguns traducianistas dos séculos XVI E XVII}

O mito do dilúvio e de Noé foi amplamente usado pelos biogeógrafos traducianistas nos séculos passados como uma explicação usual para a origem das faunas: os animais salvos na arca de Noé, ao reproduzirem-se e aumentarem gradualmente suas populações, foram capazes de gradativamente recolonizar todo o mundo e, pela dispersão, chegaram aos mais afastados pontos dos continentes. Segundo a interpretação mais 
amplamente mantida do texto sagrado, o dilúvio foi um evento universal, tendo afogado todos os homens e animais deixados fora da arca de Noé. A partir do novo "centro de origem" no Monte Ararat (o primeiro centro fora o Jardim do Éden), os animais salvos pelo patriarca reocuparam a face da Terra. O décimo e décimo primeiro capítulos do livro do Gênese contam como todos os homens descendem de Noé e de seus três filhos e como eles fizeram seu caminho da Armênia (onde está situado o Ararat) para seus países atuais.

A descoberta da América causou sérios problemas aos filósofos europeus, por mostrar uma fauna muito diferente daquela do Velho Mundo, e também porque nela existiam seres humanos. Como poderiam homens e animais ter chegado ao continente americano, após sair da arca de Noé?

Santo Agostinho, baseando-se em considerações físicas e teológicas, tinha simplesmente negado a possibilidade da presença de homens e animais no hemisfério sul, se por acaso existisse terra naquele hemisfério (cf. Papavero, Teixeira \& Llorente-Bousquets, 1997, p.31-5). Dentre as razões teológicas, está a conhecida questão dos antípodas, supostos homens, como disse Lactâncio, “cujos pés estão por cima de suas cabeças". Com base nas Escrituras, Santo Agostinho considerou impossível a existência de tais criaturas já que, estando isolados pela intransponível zona tórrida, não teriam acesso à palavra de Deus levada pelos apóstolos.

Entre os traducianistas, foram feitas várias tentativas de evitar tal problema. A mais antiga postulava uma "parte intercontinental", representada pela Atlântida de Platão, que unia o estreito de Gibraltar à América. Pela Atlântida, os homens e animais foram capazes de dispersar-se, alcançando o continente americano, onde se estabeleceram. Posteriormente, a Atlântida foi submersa pelo grande Oceano (que, por essa razão, recebeu o nome de "Atlântico"), deixando os dois continentes inexoravelmente separados até a época em que os ibéricos descobriram o "Novo Mundo" por volta do fim do século XV e início do século XVI.

Essa idéia foi defendida, entre outros, por Girolamo Fracastoro em seu poema de 1530 Syphilidis sive de morbo gallico (Sífilis ou a doença gálica). Nos versos 265-287 do livro III desse poema, que trata da origem americana da sífilis, o autor adota a idéia de que os índios americanos são descendentes dos atlantes:

Talvez haja chegado a vossos ouvidos o nome de Atlântida; pois provinha dessa antiga descendência racial (do rei Atlante). Também nós (os índios americanos), diz-se, saímos dessa estirpe, através de uma longa sucessão de gerações desse povo a um tempo feliz e querido dos deuses, enquanto seus maiores veneravam o céu e costumavam fazer aos deuses, piedosamente, gratas oferendas. Mas depois que os descendentes, com o fausto e os dissolutos costumes, começaram a ofender 
os deuses, tais e tantas calamidades os perseguiram; por essa causa, difícil serme-ia abarcá-la em meu relato. A ilha, então chamada Atlântida, do nome de um antigo rei, sacudida por um grande terremoto, afundou, tragada pelo oceano, que ela sulcava com seus navios, rainha da terra e do mar (apud Papavero, 1991, p. $5^{3}$ ).

Na Historia general de las Indias (História geral das Índias), de 1553, Francisco López de Gónara acrescenta a essa idéia de Francastoro a sugestão de que os novos continentes descobertos e a Atlântida formavam um único bloco continental (cf. Papavero, 1991, p. 57). Em 1555, Agustin de Zárate utiliza a mesma idéia em sua Historia del descubrimiento y conquista del Perú (História da descoberta e conquista do Peru) para explicar a origem dos povos peruanos:

A dúvida que costumam ter sobre averiguar por onde poderiam passar às províncias do Peru os povos que desde os tempos antigos neles habitam, parece que é satisfeita por uma história contada pelo divino Platão de modo sumário no livro intitulado Timeu De Natura, e depois ampla e copiosamente em outro livro, o diálogo que segue imediatamente ao Timeu, chamado Atlântico (apud Papavero, Teixeira \& Llorente-Bousquets, 1997, p. 38).

Justus Lipsius (nome latinizado de Joest Lips), filólogo e humanista clássico que procurou reviver o estoicismo antigo de modo a torná-lo compatível com o cristianismo, admitiu em sua obra Physiologiae stoicorum libri III (Três livros de fisiologia dos estóicos) (1637) que homens e animais teriam passado do velho ao novo mundo através de Atlântida antes que fosse tragada pelo Mar Oceano e John Swan, em seu Speculum mundi (Espelho do mundo) (1644), diz: “...penso que se pode supor que a América foi em algum tempo parte da grande terra que Platão chamou a ilha Atlântica e que os reis daquela ilha tinham alguma relação com os povos da Europa e da África". (apud Papavero, 1991, p. 60).

Essa hipótese foi intensamente atacadada pelo padre Joseph d'Acosta $(1588,1590$, 1985), que postulou que a passagem de homens e animais para a América ocorreu pelo estreito de Anian (estreito de Bering), vindo a partir da Ásia (e originalmente a partir dos casais transportados por Noé em sua arca (cf. Browne, 1983; Papavero, 1991, p. 68-74; Papavero, Llorente-Bousquets \& Espinosa-Organista, 1995b, p. 73-80; Papavero, Teixeira \& Llorente-Bousquets, 1997, p. 41-6). Essa alternativa foi endossada por vários autores subseqüentes, dentre eles Don Antonio de Herrera y Tordesillas que publica em 1601 a Historia general de los hechos de los Castellanos entre islas i tierra firme del mar Océano (História geral dos feitos dos Castelhanos entre ilhas e terra firme do mar Oceano), Walter Raleigh - 1614, - no seu History of the world (História do mundo), Georg 


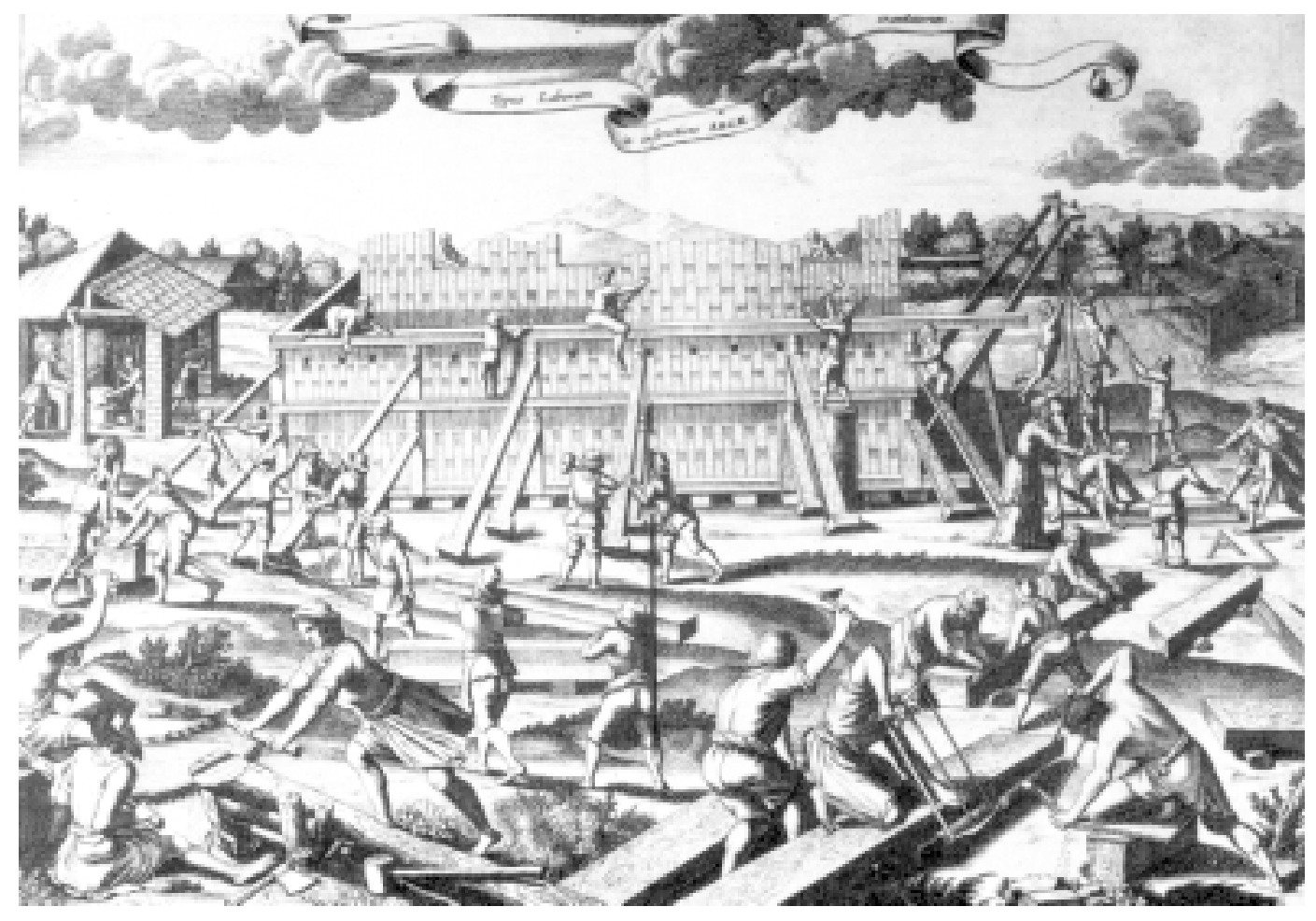

Figura 3: Construção da Arca de Noé na concepção de Athanasius Kircher.

Horn, em 1652, com De originibus americanis libri quatuor (A origem dos americanos em quatro livros) e, em 1666, com Arca Noé sive historia imperiorum et regnorum a condito orbe ad nostra tempora (A arca de Noé ou História do império e do reino sob as condições do orbe em nossa época) e o padre jesuíta Atanasio Kircher [figura 3], em 1675, em seu famoso livro Arca Noё (cf. Kircher, 1989). (Cf. Papavero, Teixeira \& Llorente-Bousquets, 1997, p. 47-118; Papavero, Pujol-Luz \& Llorente-Bousquets, 2001a, p. 141-219).

\section{O Griacionismo de IsaAg de LA Peyrère}

Em 1655, apareceu a primeira proposta criacionista concreta para explicar a diversidade das raças humanas e sua distribuição no trabalho de Isaac de la Peyrère que tinha o extenso título de Praedamitae sive exercitatio supra versibus 12, 13 et 14 capitis VEpistolae D. Pauli ad romanos, quibus indicantur primi homines ante Adamum conditi (Pré-adamitas ou exercício sobre os versículos 12, 13 e 14 do capítulo $V$ da epístola de Paulo aos romanos, no qual se indica a condição dos primeiros homens anteriores a Adão). 
La Peyrère estava a serviço de Luís II, príncipe de Condé, um dos grandes generais do rei Luís XIV. Com o príncipe, tomou parte em várias batalhas e viajou pela Espanha e Holanda (Netherlands). Foi neste último país que ele publicou seu trabalho sobre os "pré-adamitas". Como estava claramente enunciado no próprio título do trabalho, La Peyrère inspirou-se, para construir sua hipótese, nas seguintes linhas da Epistola de Paulo aos Romanos (5, 12-14):

Portanto, assim como o pecado entrou no mundo por meio de um homem, e a morte por meio do pecado, e desse modo a morte chegou a todos os homens, porque todos pecam - pois antes da lei ter sido dada, o pecado estava no mundo. Mas o pecado não é levado em conta quando não há lei.

Entretanto, a morte reinou do tempo de Adão ao tempo de Moisés, mesmo sobre aqueles que não pecavam por romper uma ordem como fez Adão, que foi o padrão daquele que estava por vir.

La Peyrère interpretou essa passagem como uma prova de que Adão não tinha sido o primeiro homem criado, mas somente o primeiro da raça judaica, tendo sido precedido (na China, na América, na Groenlândia etc.) por muitas nações - “os préadamitas" - cada qual criada direta e simultaneamente por Deus, em sua própria região. De modo análogo, a fauna e a flora dessas regiões foram criadas separada e simultaneamente em cada parte da Terra. O dilúvio, continuava La Peyrère, não tinha sido universal, mas apenas local, afogando apenas os descendentes de Adão, nas terras bíblicas; enquanto o resto do mundo foi excetuado da catástrofe, pois não tinha pecado, como era aparentemente declarado pelo apóstolo Paulo. La Peyrère levantava, desse modo, a hipótese de que Deus tinha criado várias regiões biogeográficas separada e simultaneamente e todos os povos da Terra de maneira similar. Essa idéia, em maior ou menor grau, foi adotada por certos biogeógrafos do século XIX, que propuseram a divisão da superfície da Terra em "centros de criação" - ou o que hoje chamamos de "regiões e subregiões biogeográficas".

Não é preciso dizer que uma publicação com tais idéias revolucionárias foi condenada pelo Parlamento de Paris a ser queimada e seu autor teve de fugir para Bruxelas, onde foi preso. La Peyrère consegue finalmente o perdão por suas faltas com a promessa de ir até Roma apresentar-se pessoalmente diante do papa Alexandre II e de publicar um livro com a confutação de suas idéias anteriores. E assim ele fez. Em 1657, publica seu novo livro Epistola ad Philotinum qua exponit rationes propter quas ejuravit sectam Calvini et Librum de Preadamitis (Epistola a Filotino na qual expõe as razões próprias pelas quais confuta a seita de Calvino e o livro dos pré-adamitas), que seis anos depois foi traduzido para o francês com o título Apologie de la Peyrère faite par lui-même (Apologia 
de La Peyrère feita por ele mesmo). Após a permissão de retornar à França, tornou-se o livreiro do príncipe de Condé (cf. Papavero \& Pujol-Luz, 1997, p. 133-4; Papavero, Pujol-Luz \& Llorente-Bousquets, 2001b, p. 135-6).

\section{OUtros Griacionistas}

Apesar da censura e da retratação de seu autor, a hipótese de La Peyrère obteve difusão. O naturalista holandês Abraham van der Mijl (latinizado para Mylius), em 1667, usou algumas das idéias de La Peyrère em seu trabalho De origine animalium et migratione populorum (Da origem dos animais e das migrações dos povos), no qual sustentava que tanto os homens como os animais tinham vivido no Novo Mundo desde o começo dos tempos; eles nunca passaram, vindos do oriente, para a América. Segundo Mijl, existiram várias criações, e não apenas uma, e o dilúvio não tinha obviamente sido universal, mas apenas um evento local (cf. Chiquieri, Papavero \& Teixeira, 1998, p. 255-310).

Que o dilúvio não tinha sido universal é a posição também sustentada no Origines sacrae or a rational account of the grounds of Christian Faith (Origens do sagrado ou uma descrição racional das bases da Fé Cristã) (Londres, 1662) pelo bispo protestante Edward Stillingfleet, autor conhecido por sua polêmica acerca da inadequação da filosofia de Locke à fé cristã. A obra, que se tornou bastante popular, defende a autenticidade e a credibilidade das Escrituras e, em sua terceira e última parte, Stillingfleet desenvolve uma história da formação do mundo. Matthew Poole, pastor presbiteriano, autor da Synopsis criticorum aliorumque Sacrae Scripturae interpretum (Sinópse crítica dos outros intérpretes das Sagradas Escrituras) (Londres, 1669), também apoiou a mesma idéia.

Posteriormente a idéia também foi sustentada pelo protestante francês Jean Le Clerc, no livro Commentarii philologici et paraphrases in Veterum Testamentum (Comentários filológicos e paráfrases do Velho Testamento), publicado em Amsterdã, de 1690 a 1731.

\section{Traducianismo e a origem do homem na América}

Os autores mais ortodoxos insistiam obviamente que todos os povos do mundo descendiam dos três filhos de Noé. Sua principal preocupação era saber de qual nação do Velho Mundo descendiam as tribos do Novo Mundo. Assim, o filólogo E. Brerewood, em seu livro de 1614 intitulado Enquiries touching the diversity of languages and religions through the chief parts of the world (Investigações relativas à diversidade das linguas e das religiões nas principais partes do mundo), admitia que os índios americanos descendiam de um antigo estoque de Cíntias, que se teriam transferido para a América a partir da Armênia. 
Hugo Grócio, em De origine gentium americanarum (A origem dos povos americanos), publicado em Paris e Amsterdã, no ano de 1642, critica a opinião de Brerewood (cf. Goldsmidt, 1884; Papavero, Llorente-Bousquets \& Teixeira, 1997):

Observo que existem muitos que pensam que todas essas tribos [da América] vieram da Cíntia, que agora chamamos de Grande Tartária. Eles baseiam seu argumento no fato de que, no estreito de Anian (estreito de Bering) - fosse ele um estreito ou uma baía (o que não está claro) - não existe um grande hiato entre a Tartária e a América.

Isto, segundo Grócio, é totalmente inadmissível:

...é certo que, antes da chegada dos espanhóis, não existiam cavalos na América. A Cíntia é uma região sempre repleta de cavalos e quase todos os cíntias estavam acostumados a cavalgar e a viajar por longas distâncias com sua ajuda, e até mesmo a beber o sangue de seus cavalos quando faltava qualquer outro líquido de tipo diferente. Se a América e a Tartália estivessem tão próximas, os cavalos, seja escapando ou locomovendo-se livremente, há muito tempo teriam encontrado seu caminho da Tartária à América, como aconteceu, segundo os registros dos espanhóis. Após terem introduzido os cavalos, esses animais penetraram algumas regiões da América vindos de outras regiões, mesmo quando essas regiões estavam separadas por altas cadeias de montanhas. Mas se um estreito contínuo existiu, como acredito, a Tartária nunca teve navegadores; e, se tivesse tido, eles nunca o teriam atravessado sem trazer cavalos, e nunca se sentiriam felizes de permanecer sem cavalos por longo tempo.

Uma vez eliminada essa hipótese (originalmente proposta por Joseph d' Acosta), uma hipótese melhor embasada (segundo ele) foi proposta por Grócio. Com base em similaridades lingüísticas e comportamentais forçadas entre os povos do Velho e do Novo Mundos, ele propunha outra origem para as tribos americanas. Antes de fazêlo, ele separou os povos indígenas da América em dois grandes grupos - aqueles que habitam a região norte do istmo do Panamá e aqueles que habitam a porção sul. As tribos situadas ao norte do istmo do Panamá, em sua opinião, descendem claramente dos noruegueses - e isso poderia ser demonstrado por similaridades linguísticas entre a linguagem americana e norueguesa. Os noruegueses, dizia Grócio, teriam conquistado a Groenlândia por volta do ano 1000, que se tornou então a Groenlândia e depois "Statiland", uma parte do continente americano. Portanto, a partir de Friesland (Vriesland), os noruegueses antigos alcançaram "Statiland" dois séculos antes dos es- 
panhóis, originando aí as tribos americanas. A prova, ele insistia, poderia ser encontrada nos nomes das cidades americanas (mais propriamente mexicanas): Cimatlan, Coatlan, Guescolan, Artlan, Quaxualtlan, Zuotlan, Icatlan, Tapatlan, Cinacatlan, Necotitlan, Magitlan, Tunoxcaltitlan, Ocotlan, Aitlan, Curcatlan - todas originalmente terminadas por "land"; os espanhóis, com sua pronúncia defeituosa, levaram à supressão do "d" final de "land". Nada mais natural que homens originários de "Vriesland", passando por "Iceland", para "Greenland" e "Statiland" nomeassem regiões e cidades da América de "Cimatland", "Coatland", "Tapatland" etc. Grócio acrescentava outras "evidências" análogas, baseadas em similaridades aparentes de comportamento, governo etc. entre os índios americanos (os astecas, nesse caso) e seus "ancestrais noruegueses". Mesmo o ritual de sacrifício de seres humanos, enfatizado por Grócio, mostrava sua descendência dos povos germânicos, e "com a selvageria [esse hábito] tornou-se mais desenvolvido e a ele foi acrescentada a prática de comer carne humana”. Os habitantes de Yucatan, por outro lado, na visão de Grócio, descendiam dos etíopes. Alguns pescadores, navegando ao longo da costa africana, devem ter sido lançados naquela península mexicana por fortes ventanias. Como evidências de sua origem etíope estava o fato de que as tribos de Yucatan praticavam a circunsição e faziam batizar seus filhos... No que se refere às tribos sul-americanas, duas origens diferentes foram propostas pelo autor. As tribos a leste dos Andes descenderiam das tribos indígenas do norte do istmo do Panamá - e, portanto, indiretamente, dos noruegueses. Os peruanos (os incas), entretanto, com "mentes de maior refinamento" e "capazes de um governo mais extenso e mais justo", descenderiam dos chineses, "raça de igual elegância e com a mesma habilidade imperial". Como evidências para uma tal asserção, Grócio apresenta:

a adoração solar, generalizada entre os peruanos antes da chegada dos espanhóis, assim como entre os chineses desde tempos imemoriais. Assim como o rei dos chineses é tido como filho do Sol, assim também os incas do Peru se diziam filhos do Sol;

e ainda:

a escrita dos peruanos não se utiliza de letras, mas de desenhos que denotam coisas e, tal como na China, do alto ao baixo do papel.

Finalmente, coroando seu trabalho, Grócio afirma acreditar que: 
Mancacapacus [Manco Capac] era um chinês que, sendo um homem de espírito e engenho maravilhosos, ao saber que homens de sua própria raça possuíam boas terras do outro lado do mar, mas que não tinham governo apropriado, dirigiu-se para lá, uniu-os e deu-lhes um tipo de governo segundo o modelo da China.

Jean de Laet (Laetius), em seu Notae ad dissertationem H. Grotti de origine gentium americanarum (Notas à dissertação de H. Grócio sobre a origem dos povos americanos), publicado em Paris e Amsterdã, em 164,3, critica essas idéias, sugerindo que os índios americanos descendiam dos persas. Grócio respondeu, nesse mesmo ano, com a Dissertatio altera (Outra dissertação), seguida por outra crítica de Laet em 1644 .

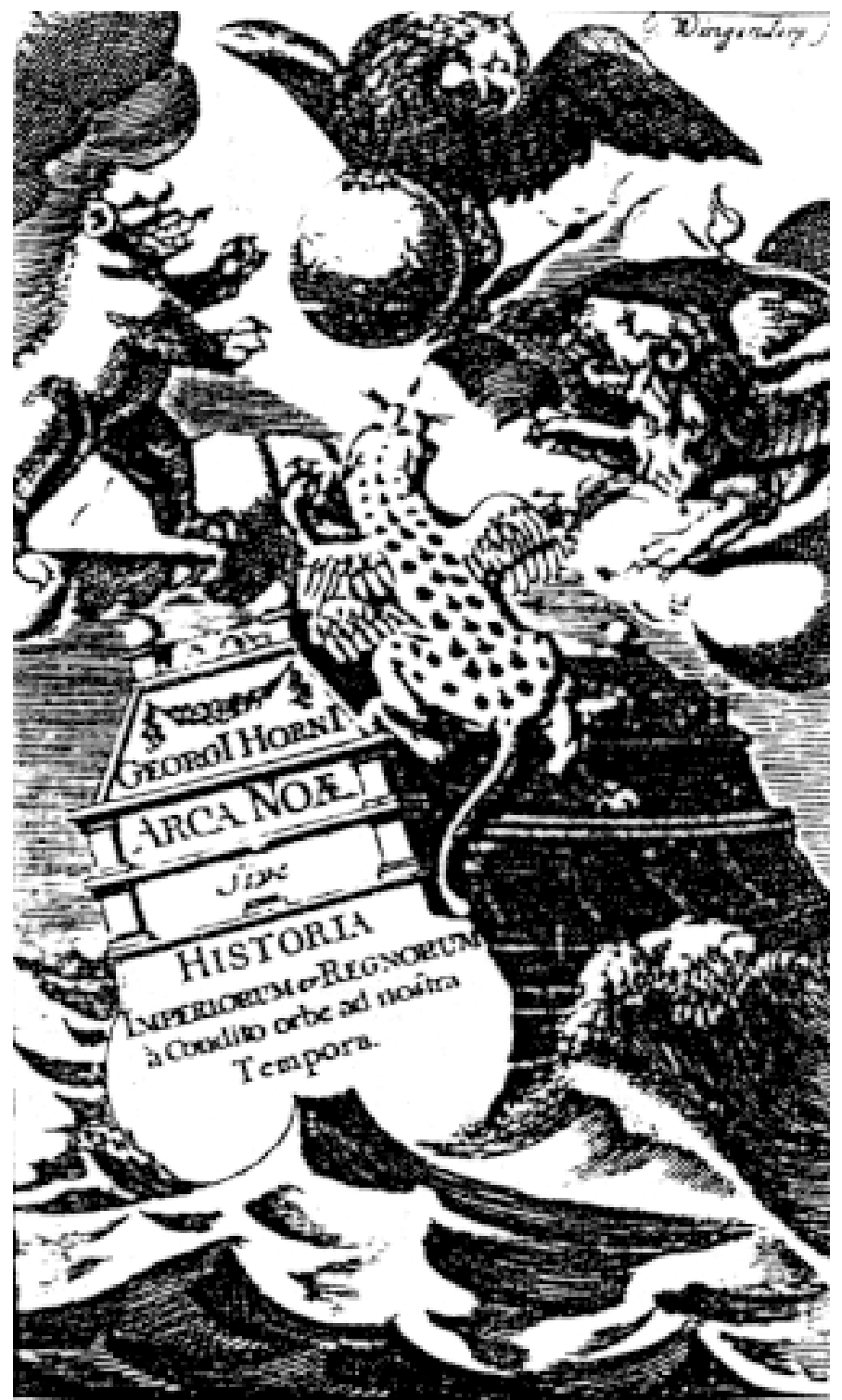

Lugd.Batav.] et PotzROD.

Outros estudiosos da época, como é o caso de Hornius, que publica em 1652 , em Leyden, De originibus americanis libri quatuor ( $A$ origem dos americanos em quatro livros), admitiram invasões sucessivas da América pelos fenícios, chineses e Cíntias, cada um desses invasores tendo ocupado o Novo Mundo por sua vez, para degenerar apenas mais tarde misturandose com os outros. Em seu livro, Arca Noe sive historia imperiorum et regnorum a conditio orbe ad nostra tempora ( $A$ arca de Noé ou história do império e do reino sob as condições do orbe em nossa época) de 1666 [figura 4], Hornius desenvolve esse mesmo tipo de hipótese interpretativa, afirmando que os animais que vieram da arca de Noé passaram à América durante o inverno, quando os mares do norte estão congelados.

Figura 4: Frontispício de $A$ Arca de Noé ou história do império e do reino sob as condições do orbe em nossa época de Georg Horn, editada em 1666. 


\section{O traducianismo de Matthew Hale}

Com a publicação, em Londres, em 1677, do livro The primitive origination of mankind considered and examined according to the light of nature (A origem primitiva da humanidade considerada e examinada segundo a luz da natureza), sir Matthew Hale pretendia refutar os "princípios morais" e irreligiosos "contidos nos trabalhos de La Peyrère e outros autores abomináveis. Seu argumento era extremamente simples: os seres humanos aumentam em número, a cada geração, por reprodução; invertendo o quadro, notaremos que, a cada geração, o número de seres humanos torna-se menor do que as gerações posteriores; este processo leva necessariamente à conclusão de que todos os seres humanos devem provir de um único casal original - Adão e Eva - tal como revelado pela Bíblia. É totalmente evidente que esse casal não poderia provir de nenhum outro; logo, segue-se a necessidade de um Criador. $\mathrm{O}$ mesmo argumento pode ser estendido a todas as espécies animais. Cada uma delas deve provir de um único casal original - os casais salvos na arca de Noé (e antes disso, criados diretamente por Deus no Jardim do Éden). Esse simples cálculo, diz Hale, refuta todas as vãs hipóteses propostas até então e confirma a verdade literal do livro do Gênese.

A fauna americana, segundo Hale, formou-se pela migração dos elementos provindos dos casais primordiais de cada espécie tomada na arca de Noé, que possivelmente degenerou subseqüentemente por hibridização, pela influência de fatores ambientais etc. De outro modo, as espécies da América do Sul seriam as mesmas que aquelas de outras partes do mundo, tal como a África e a Ásia. Isso seria demonstrado quando aqueles continentes fossem melhor explorados.

Lineu, na primeira edição do Systema Naturae (Sistema da natureza) de ${ }_{17} 3_{5}$ [figura 5 ], nas Observationes in regna naturae III (Observações sobre o reino da natureza III), aceitou inteiramente as considerações de Hale:

1. Se consideramos atentamente a obra de Deus, a todos [está] suficientemente evidente que a vida de cada um se multiplica a partir do ovo e todo ovo produz rebento similar aos pais. Daí que não se produz nenhuma nova espécie atualmente.

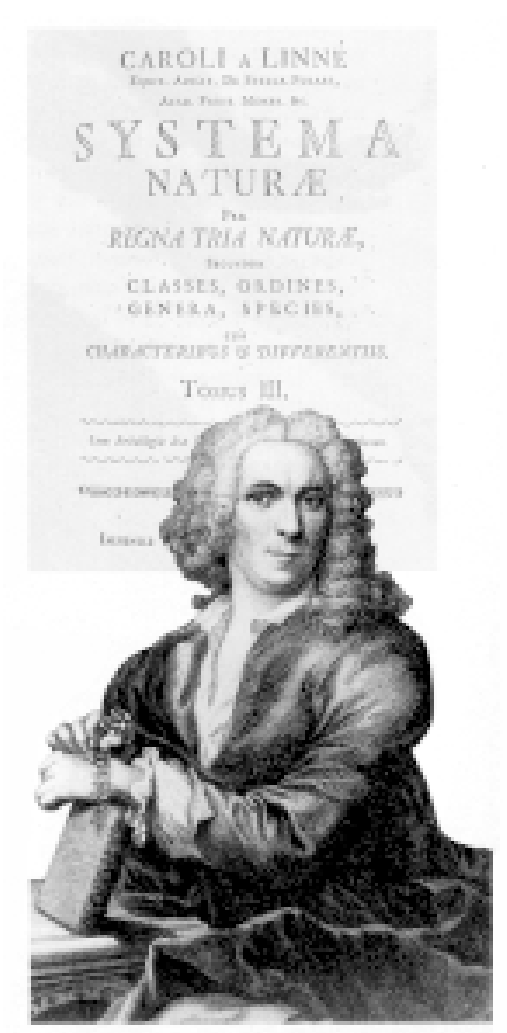

Figura 5: Lineu e o Sistema da natureza. 
2. A partir da geração os indivíduos se multiplicam. Daí que é maior neste tempo o número de indivíduos em cada espécie que no tempo anterior.

3. Se enumerarmos regressivamente esta multiplicação de indivíduos de uma espécie qualquer, do modo como já multiplicamos progressivamente (2), a série termina num único parente, seja um parente constituído de um único hermafrodita (como é comum nas plantas), seja a partir de uma dupla, a saber, de macho e fêmea (como na maioria dos animais).

4. Posto que (1) nunca apareceram novas espécies e (2) como o semelhante sempre se parece com seu semelhante e (3) como a unidade em cada espécie leva à ordem, é necessário que atribuamos aquela unidade progenitora a algum ente onipotente e onificiente, seguramente a Deus, de cuja obra a Criação é parte. Confirmam isso os mecanismos, as leis, os princípios, as constituições e as sensações em cada indivíduo vivente.

\section{A originalidade DA PROPOSTA DE VON HÜPSGH}

Este breve panorama do pensamento biogeográfico do século XVI ao XVIII mostra como foi intensa a discussão acerca dos povos e da biota das Américas, tal como enfatizado pelo barão von Hüpsch na dedicatória de seu livro: "A união do velho e novo mundos e o povoamento das Índias Ocidentais (Américas) são um ponto útil e importante da História".

Apesar de encontrarmos alguns elementos comuns no pensamento biogeográfico do autor e de seus predecessores, há certos aspectos no primeiro que sugerem importantes inovações. Nos traducianistas anteriormente apresentados, a defesa tanto dos centros de origem e dispersão como da comunidade de descendência das espécies tinham um claro fundo teológico envolvido. Em von Hüpsch estas questões saem de foco e seu texto concentra-se na tentativa de explicar a separação das biotas do antigo e do novo mundo, bem como da biogeografia das ilhas, a partir de evidências geológicas positivas (mas que não dispensam narrativas históricas clássicas como as de Platão).

Mas há também uma diferença ainda mais significativa. Se considerarmos o conjunto da obra, nela perceberemos uma espécie de combinação de duas explicações biogeográficas distintas: aquela que recorre ao fenômeno da dispersão das populações - dominante nos autores anteriormente citados - e aquela cujo pleno desenvolvimento científico ocorrerá somente no século XX, que explica a distribuição atual das espécies postulando a partição de populações já estabelecidas no passado. Isso pode ser visto, por exemplo, no parágrafo 10 quando von Hüpsch, referindo-se a Inglaterra, Sicília, Madagascar, Bornéu, Sumatra, Japão, Cuba, Hispaniola e Nova Zelândia, diz: "Os animais quadrúpedes que já se achavam numa ou noutra dessas ilhas por ocasião 
da inundação permaneceram ali, porque seu caminho de volta fora cortado pela inundação. Como resultado, ficaram isolados nas ilhas recentemente formadas e separados da terra firme, e propagaram sua espécie".

Somente no início do século XX, com a teoria da deriva continental de Wegener, a hipótese de uma união anterior das grandes massas continentais num único supercontinente exerceria novamente influência sobre o pensamento biogeográfico, culminando na teoria moderna da biogeografia vicariante.

Na seqüência, portanto, apresentamos a tradução desse importante texto do barão von Hüpsch, para o prazer dos leitores.

\title{
Nelson Papavero
}

Museu de Zoologia da Universidade de São Paulo.

\author{
Pablo Rubén Marigonda \\ Professor Associado do Departamento de Filosofia \\ da Universidade de São Paulo, \\ coordenador do Projeto Temático "Estudos de filosofia \\ e história da ciência" da FAPESP. \\ ariconda@usp.br

\section{Maurício de Garvalho Ramos} \\ Pesquisador do Projeto Temático \\ "Estudos de filosofia e história da ciência" da FAPESP, \\ pós-doutorando do Departamento de Filosofia \\ da Universidade de São Paulo. \\ maucramos@usp.br
}

\section{REFERÊNGIAS BIBLIOGRÁFIGAS}

d'ACOSTA, J. De natura novi orbis libri duo. De promulgatione evangelii apud Barbados, sive de procuranda indorum salute libri sex. Salamanca, Gullielmum Foquel, 1588 .

Historia natural y moral de las Indias, en que se tratan de cosas notables del cielo, elementos, metales, plantas y animales dellas, y de los ritos y ceremonias, leyes y gobierno de los indios. Devilla, Juan de Léon, 1590 .

d'ACOSTA, J. Historia natural y moral de las Indias, en que se tratan de cosas notables del cielo, elementos, metales, plantas y animales dellas, $y$ de los ritos y ceremonias, leyes y gobierno de los indios. Cidade do México, Fondo de Cultura Económica, 1985. 
ANÔNIMO. Tourist guide. grece. Antiquies. History. Monuments. Museums. Sites. Tours. Camping and tourist map. Atenas, Mathioulakis, s./d.

Bíblia. Tradução ecumênica. Ed. de G. G. Galache \& J. Konings. São Paulo, Loyola, 1997.

BREREWOOD, E. Enquiries touching the diversity of the languages and religions of the world. Londres, J. Bill, 1614 .

BROWNE, J. The secular ark. Studies in the history of biogeography. New Haven/Londres, Yale University Press, 1983.

BUFFON, G.-L. de. De la dégénération des animaux. In: Oeuvres de Buffon. Ed. de J. Pizzetta, 1868. URL: http://gallica.bnf.fr/scripts, obtido em $02 / 09 / 2003$.

. Oeuvres de Buffon. Ed. de J. Pizzetta, 1868.

CHIQUIERI, A.; PAPAVERO, N. \& TEIXEIRA, D. M. "Abraham van der Myl et son De origine animalium et migratione populorum”. Historia naturalis, 1, 1998, p. 255-310.

GOLDSMIDT, E. D. (ed.). Bibliotheca curiosa. Edinburgh, [Private Edition], 1884.

GROCIO, H. Hugonis Grotii dissertatio de origine gentium americanarum. Paris, 1642.

"On the origin of the natural races of America". In: GOLDSMIDT, E. D. (ed.). Bibliotheca curiosa. Edinburgo, [Private Edition], 1884.

HALE, M. The primitive origination of mankind considered and examined according to the light of nature. Londres, W. Shrowsbery, 1677 .

HORN, G. Georgi Horni De originibus americanis libri quator. Hague, Adriani Vlacq, 1652. . Arca Noe sive historia imperiorum \& regnorum a condito orbe ad nostra tempora, Leyden, 1666.

HÜPSCH, J. W. C. A von. Physikalische Abhandlung von der vormaligen Verknüpfung und Absomderung der alten und neuen Welt, und der Bevölkerung Westindies; nebst einer physikalischen Untersuchung von dem Ursprung der Seen. Cöln am Rheine, Lohan Heinrich Hartz, 1764a.

. Geophänomenologie, oder die Lehre von denen grossen natürlichen Begebenheiten, welche sich bey der Erde ereignen, historisch und physisch entworfen von... Cöln am Rheine, Lohan Heinrich Hartz, 1764,b. . Neue in der Naturgeschichte des Nieder-Deutschlandes gemachte Entdeckungen einiger seltener und wenig bekannten versteinerten Schaalthiere, zur Eiweiterung und Ergänzung des Thierreiches beschrieben. Frankfurt/Leipzig, 1768.

. Nouvelles découvertes de quelques testacés pétrifiés rares et inconnus, pour servir à l'histoire naturelle de la Basse-Alemagne et enrichir les colletions du règne animal. Frankfurt/Leipzig, Köln, 1771.

ILLIES, J. Introduction to zoogeography. Londres/Basingstoke, The MacMillan Press, 1974.

KIRCHER, A. Arca Nöe in tres libros digesta. Amsterdã, Joannem Janssonium, 1675.

El arca de Noe. El mito, la naturaleza y el siglo XVII. Trad. e ed. de A. M. Tomé. Madri, Ediciones Octo, 1989 .

KRÜGER, J. G. Geschichte der Erde in den allerälteste Zeiten. Halle, 174,6.

LAET, H. de. Joannis de Laet antwerpiane notae ad dissertationem Hugonis Grotii De origine gentium americanarum et observationes aliquot at meliorem indaginem difficillimae illius quaestiones. Amsterdã, Ludovicum Elzevirum, 1643.

LA PEYRÈRE, I. Preadamitae sive exercitatio super versibus 12, 13 et 14 capitis quinti Epistolae D. Pauli ad romanos, quibus indicantur primi homines ante Adamum conditi. Paris, 1665 .

LIPSIUS, J. “Physiologiae stoicorum libri III”. In: LIPSIUS, J. Opera omnia. Antuerpia, Ex Officina Platin, 1637 .

. Opera omnia. Antuerpia, Ex Officina Platin, 1637 .

MYL, A. van der. De origine animalium et migratione populorum. Genebra, Petrum Colomesium, 1667 .

OVÍDIO. Metamorphoses. Trad. de A. D. Melville. Introd. e notas de E. J. Kenney. Oxford World’s Classics. Oxford, Oxford University Press, 1986. 
PAPAVERO, N. Introdução histórica à biologia comparada, com especial referência à biogeografia. Vol. III. De Nicolás de Cusa a Francis Bacon (1493-1634). Rio de Janeiro, Editora Universitária Santa Úrsula, 1991. PAPAVERO, N. \& BALSA, J. Introdução histórica à biologia comparada, com especial referência à biogeografia. Vol. I. Do gênesis à queda do império romano do ocidente. Belo Horizonte, Biótica \& Sociedade Brasileira de Zoologia, 1986.

PAPAVERO, N.; LLORENTE-BOUSQUETS, J. \& ESPINOSA-ORGANISTA, D. Historia de la biología comparada desde el génesis hasta el siglo de las luces. Vol. I. Del génesis hasta la caída del imperio romano de occidente. Cidade do México, Universidad Nacional Autónoma de México, 1995a.

. Historia de la biología comparada desde el génesis hasta el siglo de las luces. Vol. III. De Nicolás de Cusa a Francis Bacon (1493-1634). Cidade do México, Universidad Nacional Autónoma de México, 1995b.

PAPAVERO, N. LLORENTE-BOUSQUETS, J. \& TEIXEIRA, D. M. "Una curiosidad histórica: el 'De originae gentium americanarum' de Hugo Grotius". Revista de la Universidad Nacional Autónoma de México, $554-555,1997$, p. 42-6.

PAPAVERO, N. \& PUJOL-LUZ, J. R. Introdução histórica à biologia comparada, com especial referência à biogeografia. Vol. IV. De Descartes a Leibniz (1628 a 1716) . Seropédica, Editora Universidade Rural, 1997. . Introdução histórica à biologia comparada, com especial referência à biogeografia. Vol. V. O século das luzes (Parte I). Seropédica, Editora Universidade Rural, 1999.

. Introduçào histórica à biologia comparada, com especial referência à biogeografia. Vol. VI. O século das Luzes (Parte II). Seropédica, Editora Universidade Rural, 2000.

PAPAVERO, N., PUJOL-LUZ, J. R. \& LLORENTE-BOUSQUETS, J. Historia de la biología comparada desde el génesis hasta el siglo de las luces. Vol. IV. De Descartes a Leibniz (1628-1716). Cidade do México, Universidad Nacional Autónoma de México, 2001a.

. Historia de la biología comparada. Vol. V. El siglo de las luces (Parte I). Cidade do México, Universidad Nacional Autónoma de México, 2001b.

. Historia de la biología comparada. Vol. VI. El siglo de las luces (Parte II). Cidade do México, Universidad Nacional Autónoma de México, 2001c.

PAPAVERO, N., SCROCCHI, G. \& LLORENTE-BOUSQUETS, J. Historia de la biología comparada desde el génesis hasta el siglo de las luces. Vol. II. La Edad Media: desde la caída del imperio romano de occidente hasta la caída del imperio romano de oriente. Cidade do México, Universidad Nacional Autónoma de México, 1995.

PAPAVERO, N., TEIXEIRA, D. M. \& LLORENTE-BOUSQUETS, J. Historia da biogeografia no período préevolutivo. São Paulo, Plêiade/FAPESP, 1997.

PLÍNIO. Natural history in ten volumes. Vol. I. Paefatio, Libri I, II. With an english translation by H. Rackham, M. A. Loeb Classical Library. Londres, Harvard University Press/William Heinemann, 1967.

POOLE, M. Synopsis criticorum aliorumque Sacrae Scripturae interpretum. Londres, 1669.

QUARG, G. "Die 'Vormalige Verknüpfung und Absonderung der alten neuen Welt', eine Abhandlung des Freiherrn von Hüpsch am dem Jahre 1764". Decheniana, 36, 1983, p. 108-9.

RAVEN, C. E. John Ray, naturalist. His life and works. Cambridge, Cambridge University Press, 19422.

SCHEUCHZER, J. J. Herbarium diluvianum. Editio novissima, duplo auctior. Leyden, Petri Vander Aa, 1723.

SÊNECA. Seneca in ten volumes. Vol.X. Naturales questiones II. Trad. de Thomas H. Corcoran. Loeb Classical Library. Cambridge (Mass.)/Londres, William Heinemann/Harvard University Press, 1972.

SPRAGUE DE CAMP, L. Lost continents: the Atlantis theme in history, science and literature. Nova Iorque, Dover, 1970.

STILLINGFLEET, E. Origines sacrae or a rational account of the grounds of Christian Faith. Londres, H. Mortlock, 1662.

TERTULIANO, Q. S. F. De pallio, or On the ascetics' mantle, \& against Hermogenes. Edinburgo, Ante-Nicene Christian Library/Clark \& Clark, s./d. 